\title{
Transverse implications of maxillary premolar extraction in Class III presurgical orthodontic treatment
}

\author{
Shin-Jae Lee, ${ }^{\text {a }}$ Tae-Woo Kim, ${ }^{b}$ and Dong-Seok Nahm ${ }^{c}$ \\ Seoul, South Korea
}

Introduction: Maxillary premolars are often extracted to resolve incisor proclination in presurgical orthodontic treatment for severe skeletal Class III patients. The aim of this article was to compare arch-width changes and orthodontic tooth movements between maxillary premolar extraction and nonextraction modalities, and to provide an additional indication for presurgical maxillary premolar extraction according to the transverse dental arch characteristics of Class III surgical-orthodontic patients. Methods: Pretreatment and posttreatment dental casts of 55 adult Class III patients (24 nonextraction, 31 extraction) who underwent surgicalorthodontic treatment were collected. The changes in maxillary and mandibular dental arch widths were measured from the canines to the second molars. Orthodontic tooth movement was evaluated with an angulation-and-inclination measuring gauge. Results: Statistical analyses showed that intermaxillary arch congruity was attributed mainly to maxillary arch-width changes. The arch-width changes could be interpreted as the result of inclination changes in both posterior dentitions. For the arch-width change, analysis of covariance (ANCOVA) showed a significant extraction effect: the premolar extraction group's ability to accommodate arch-width change was significantly greater than that of the nonextraction group. Conclusions: The indications for maxillary premolar extraction in Class III presurgical orthodontic treatment might depend in part on the characteristics of the maxillary arch width and posterior teeth inclinations. (Am J Orthod Dentofacial Orthop 2006;129:740-8)

$\mathbf{M}$ andibular prognathism is the most common reason for orthodontic treatment and orthognathic surgery in Korea. Unlike North Americans, who have a low Class III prevalence, about one fifth of all Koreans have Class III malocclusions. ${ }^{1}$ However, neither growth modification nor orthodontic camouflage is known to be successful enough to correct Class III malocclusions. In 2002, 46.6\% of all Korean patients were candidates for Class III surgical-orthodontic treatment. ${ }^{2}$ With socioeconomic development and enhanced desire for facial esthetics, the number of patients seeking surgical correction has remarkably increased over the past decades. Nevertheless, our present knowledge of efficient orthodontic strategy for Class III surgical-orthodontic treatment is not yet sufficient.

From the Department of Orthodontics, School of Dentistry and Dental Research Institute, Seoul National University, Seoul, South Korea.

assistant professor.

${ }^{\mathrm{b}}$ Chairman and associate professor.

${ }^{\mathrm{c}}$ Professor.

Reprint requests to: Tae-Woo Kim, Department of Orthodontics, College of Dentistry, Seoul National University, 28-22 Yunkeun-Dong, Chongro-Ku, Seoul 110-744, Korea; e-mail, taewoo@snu.ac.kr.

Submitted, July 2004; revised and accepted, October 2004 $0889-5406 / \$ 32.00$

Copyright (C) 2006 by the American Association of Orthodontists. doi:10.1016/j.ajodo.2006.02.002
A patient diagnosed with Class III mandibular prognathism planning to undergo surgical-orthodontic treatment often has a maxillary deficiency, proclined maxillary incisors, and crowding. The natural compensatory mechanism compels the maxillary dentition to flare buccolabially, whereas, in the mandibular dentition, lingual tipping of incisors and posterior segments is generally observed. ${ }^{3,4}$ Therefore, effective elimination of preexisting dental compensation is essential in the presurgical orthodontic treatment stage to achieve functional occlusion after surgery.

During presurgical orthodontic treatment, maxillary premolars are often extracted to resolve incisor proclination and crowding. Thus, extraction of premolars had been primarily indicated to enhance esthetics. ${ }^{5}$ However, extractions can also be planned to correct incongruent arch widths. Surgically assisted rapid maxillary expansion and surgical expansion of the deficient maxilla have been indicated when the maxillary dentition will remain in crossbite after the jaw is repositioned. ${ }^{6-12}$ In this study, it is postulated that mild transverse maxillary deficiency can be treated with maxillary premolar extractions; this would result in congruent arch width with proper inclination of the posterior teeth, followed by greater anteroposterior surgical jaw repositioning. 

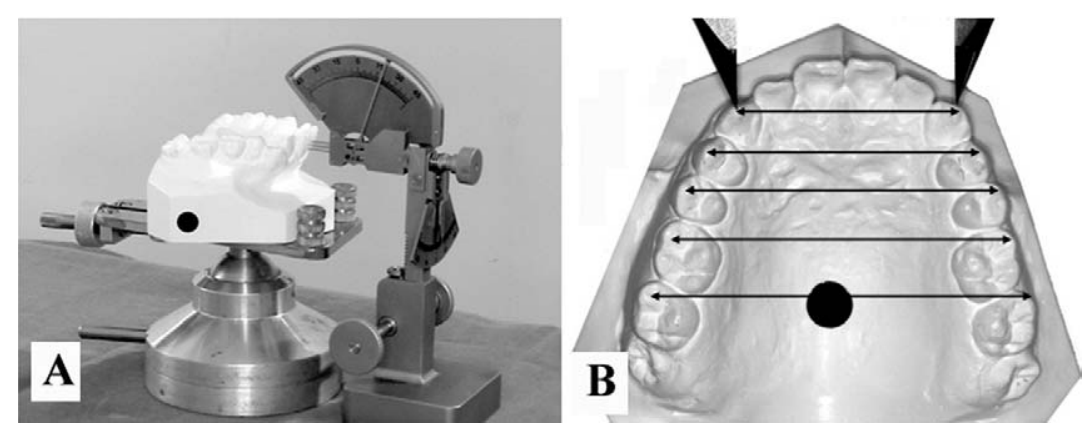

Fig 1. Dental cast analysis. A, Angulation-and-inclination measuring gauge can simultaneously record angulation and inclination of teeth; $\mathbf{B}$, arch-width measurements from canines to second molars.

Premolar extractions, incisor retraction, and archlength changes must not be considered in isolation, and their interdependence has significant implications on arch width. Maxillary premolar extraction in presurgical orthodontics will more easily correct flared posterior teeth. ${ }^{13}$ The interaction of all 3 planes of space is such that the changes in posterior teeth inclination will frequently affect the arch-width change and the amount of anteroposterior surgical jaw repositioning. It is therefore essential to assess arch widths and posterior tooth inclinations as well as maxillary crowding and alveolar protrusion to discriminate between maxillary premolar extraction and nonextraction patients.

The aim of this study was to compare arch-width changes and amounts of orthodontic tooth movement between the maxillary premolar extraction and nonextraction presurgical modalities during Class III surgicalorthodontic treatment to provide an additional indication for maxillary premolar extraction.

\section{MATERIAL AND METHODS}

Pretreatment and posttreatment dental casts of 55 adults with skeletal Class III malocclusions (24 nonextraction, 31 maxillary first premolar extraction) who underwent surgical-orthodontic treatment were collected.

Mandibular setback surgery with bilateral sagittal split ramus osteotomy was performed in all patients. In 21, total maxillary advancement with LeFort I or II osteotomy was also performed.

Patients with segmental surgery, transpalatal appliances that could surgically or orthopedically change tooth position and arch form, craniofacial anomalies or syndromes, and severe transverse problems were excluded from this study. Patients with more than $3 \mathrm{~mm}$ of tooth size-arch perimeter discrepancy, missing teeth, and exten- sive restorations were also excluded to control for confounding variables.

Evaluations of orthodontic tooth movement were divided into 3 categories: mesiodistal angulation changes; buccolingual inclination changes; and intercanine, interpremolar, and intermolar arch-width changes. The second and third categories are interrelated in forming posterior arch coordination.

Orthodontic tooth movements before and after surgical-orthodontic treatment were analyzed by using an angulation-and-inclination measuring gauge (Invisitech, Seoul, Korea) that was developed to simultaneously record angulation and inclination of a tooth on a dental cast. ${ }^{14} \mathrm{~A}$ level and a dental surveyor kit with a laboratory jack were used to ensure the flatness of the measuring field, and the dental cast was positioned parallel to the functional occlusal plane. The 3 pointers on the measuring gauge were directed toward the facial axis of the clinical crown with the middle pointer aimed toward the facial axis point as described by Andrews ${ }^{15}$ (Fig 1, A).

A digital vernier caliper with sharpened points (Mitutoyo, Kawasaki, Kanakawa, Japan) was used to measure widths between all posterior teeth, from the canines up to the second molars. A centroid was constructed for each cusp tip, which was relatively independent of cusp wear or abrasion and sensitive to both coronal translation and tipping (Fig 1, B).

\section{Statistical analysis}

Descriptive statistics with independent $t$ tests were used to determine whether there was a statistical significance in mean tooth movement and arch-width changes between the nonextraction and maxillary premolar extraction groups.

To determine the contribution of orthodontic tooth movement in explaining arch-width changes, regression analysis was performed. Although efforts were 
Table I. Comparisons of orthodontic tooth movement and arch-width change between nonextraction and maxillary premolar extraction groups in Class III surgical-orthodontic treatment

\begin{tabular}{|c|c|c|c|c|c|c|}
\hline \multirow[b]{2}{*}{ Dimensions } & \multirow{2}{*}{$\frac{\text { Nonextraction }}{D_{T 2-T 1} \pm S E}$} & \multirow{2}{*}{$\begin{array}{c}\begin{array}{c}\text { Maxillary } \\
\text { first premolar } \\
\text { extraction }\end{array} \\
D_{T 2-T 1} \pm S E\end{array}$} & \multirow{2}{*}{$\frac{\mathrm{t} \text { test }}{\text { Sig }}$} & \multirow{2}{*}{$\frac{\text { Nonextraction }}{D_{T 2-T I} \pm S E}$} & \multirow{2}{*}{$\begin{array}{c}\begin{array}{c}\text { Maxillary } \\
\text { first premolar } \\
\text { extraction }\end{array} \\
D_{T 2-T 1} \pm S E\end{array}$} & \multirow{2}{*}{$\frac{\mathrm{t} \text { tes }}{\mathrm{Sig}}$} \\
\hline & & & & & & \\
\hline & \multicolumn{2}{|c|}{ Maxillary dentition } & \multicolumn{4}{|c|}{ Mandibular dentition } \\
\hline \multicolumn{7}{|l|}{ Central incisor } \\
\hline$\Delta \mathrm{a}$ & $2.48 \pm 0.86$ & $1.95 \pm 1.08$ & & $1.07 \pm 1.16$ & $0.87 \pm 0.63$ & \\
\hline$\Delta \mathrm{i}$ & $2.05 \pm 1.39$ & $-4.25 \pm 1.53$ & $\dagger$ & $8.75 \pm 0.21$ & $9.18 \pm 1.37$ & \\
\hline \multicolumn{7}{|l|}{ Lateral incisor } \\
\hline$\Delta \mathrm{a}$ & $0.79 \pm 1.04$ & $1.86 \pm 1.49$ & & $2.63 \pm 0.75$ & $2.94 \pm 0.80$ & \\
\hline$\Delta \mathrm{i}$ & $2.91 \pm 1.75$ & $-1.33 \pm 2.00$ & & $7.35 \pm 0.99$ & $6.82 \pm 1.25$ & \\
\hline \multicolumn{7}{|l|}{ Canine } \\
\hline$\Delta \mathrm{a}$ & $-0.90 \pm 0.85$ & $-2.38 \pm 1.97$ & & $3.08 \pm 1.05$ & $4.20 \pm 0.65$ & \\
\hline$\Delta \mathrm{i}$ & $2.13 \pm 1.09$ & $-7.45 \pm 1.27$ & 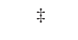 & $3.39 \pm 0.82$ & $3.02 \pm 0.79$ & \\
\hline$\Delta \mathrm{w}$ & $0.89 \pm 0.31$ & $0.84 \pm 0.40$ & & $-0.09 \pm 0.30$ & $0.60 \pm 0.28$ & \\
\hline \multicolumn{7}{|l|}{ First premolar } \\
\hline$\Delta \mathrm{a}$ & $-2.98 \pm 1.12$ & - & & $-1.65 \pm 1.15$ & $-3.18 \pm 1.12$ & \\
\hline$\Delta \mathrm{i}$ & $2.28 \pm 1.03$ & - & & $4.65 \pm 1.40$ & $3.88 \pm 1.18$ & \\
\hline$\Delta \mathrm{w}$ & $1.04 \pm 0.34$ & - & & $1.34 \pm 0.60$ & $2.45 \pm 1.04$ & \\
\hline \multicolumn{7}{|c|}{ Second premolar } \\
\hline$\Delta \mathrm{a}$ & $-2.30 \pm 0.94$ & $-1.86 \pm 0.84$ & & $-2.75 \pm 1.23$ & $-2.69 \pm 1.19$ & \\
\hline$\Delta \mathrm{i}$ & $-0.87 \pm 1.09$ & $-4.67 \pm 1.26$ & $*$ & $6.75 \pm 1.48$ & $5.12 \pm 1.68$ & \\
\hline$\Delta \mathrm{w}$ & $0.34 \pm 0.45$ & $-3.55 \pm 0.86$ & $\$$ & $2.25 \pm 0.67$ & $1.29 \pm 0.69$ & \\
\hline \multicolumn{7}{|l|}{ First molar } \\
\hline$\Delta \mathrm{a}$ & $-1.17 \pm 0.86$ & $-0.75 \pm 0.99$ & & $-2.29 \pm 1.02$ & $-3.21 \pm 0.80$ & \\
\hline$\Delta \mathrm{i}$ & $-2.63 \pm 0.96$ & $-5.15 \pm 0.72$ & $*$ & $3.94 \pm 1.50$ & $1.87 \pm 1.04$ & \\
\hline$\Delta \mathrm{w}$ & $-0.62 \pm 0.57$ & $-3.91 \pm 0.53$ & $\$$ & $1.11 \pm 0.62$ & $0.89 \pm 0.39$ & \\
\hline \multicolumn{7}{|l|}{ Second molar } \\
\hline$\Delta \mathrm{a}$ & $3.67 \pm 1.46$ & $9.10 \pm 1.49$ & $*$ & $-2.40 \pm 1.12$ & $-2.91 \pm 0.86$ & \\
\hline$\Delta \mathrm{i}$ & $-1.73 \pm 1.44$ & $-7.15 \pm 1.02$ & $\dagger$ & $3.02 \pm 0.99$ & $4.23 \pm 1.20$ & \\
\hline$\Delta \mathrm{w}$ & $-0.94 \pm 0.43$ & $-4.08 \pm 0.45$ & * & $2.08 \pm 0.48$ & $1.98 \pm 0.43$ & \\
\hline
\end{tabular}

$* P<.05,{ }^{\dagger} P<.01,{ }^{\ddagger} P<.001 ; \Delta a$, Amount of angulation change $\left({ }^{\circ}\right) ; \Delta i$, amount of inclination change $\left({ }^{\circ}\right) ; \Delta w$, amount of arch width change $(\mathrm{mm}) . D_{T 2-T l}$, Mean differences before and after treatment; $S E$, standard error of mean differences; Sig, Significant difference between groups.

made to control for confounding variables such as amount of crowding, there still might be important differences between the nonextraction and the maxillary premolar extraction groups-eg, pretreatment posterior tooth inclinations. This might explain all or part of the apparent differences in arch-width changes. Therefore, to examine the differences in arch-width changes after accounting for the preexisting characteristics of the dental arches between the 2 groups, analysis of covariance (ANCOVA) $(\alpha=0.05)$ was used. Considering the covariate, ANCOVA can correct for the bias resulting from baseline differences and remove the variance attributable to baseline variables. Power analysis indicated that our sample size was adequate.

\section{RESULTS}

An examiner (S-J.L.) with orthodontic qualifications recorded all measurements. To test interexam- iner reliability, 14 randomly selected casts were measured by another examiner (S.J.K.). These measurements were compared with the original data, and Dahlberg's formula ${ }^{16}$ was used to calculate the method error.

The main causes of measurement error occur in setting up the facial axis of the clinical crown, defining the facial axis point, and determining a point on the cusp tip. The interexaminer errors of the estimation were as follows: tooth angulation, from $0.50^{\circ}$ to $1.97^{\circ}$ with a mean of $1.36^{\circ}$; tooth inclination, from $0.16^{\circ}$ to $1.79^{\circ}$ with a mean of $0.90^{\circ}$; maxillary arch width, from 0.15 to $0.43 \mathrm{~mm}$ with a mean of $0.29 \mathrm{~mm}$; and mandibular arch width, from 0.29 to $1.60 \mathrm{~mm}$ with a mean of $0.88 \mathrm{~mm}$. Morphologically, the maxillary posterior teeth have more prominent cusp tips and developmental ridges than do the mandibular teeth; this would cause the lower measurement errors in maxillary arch width. 


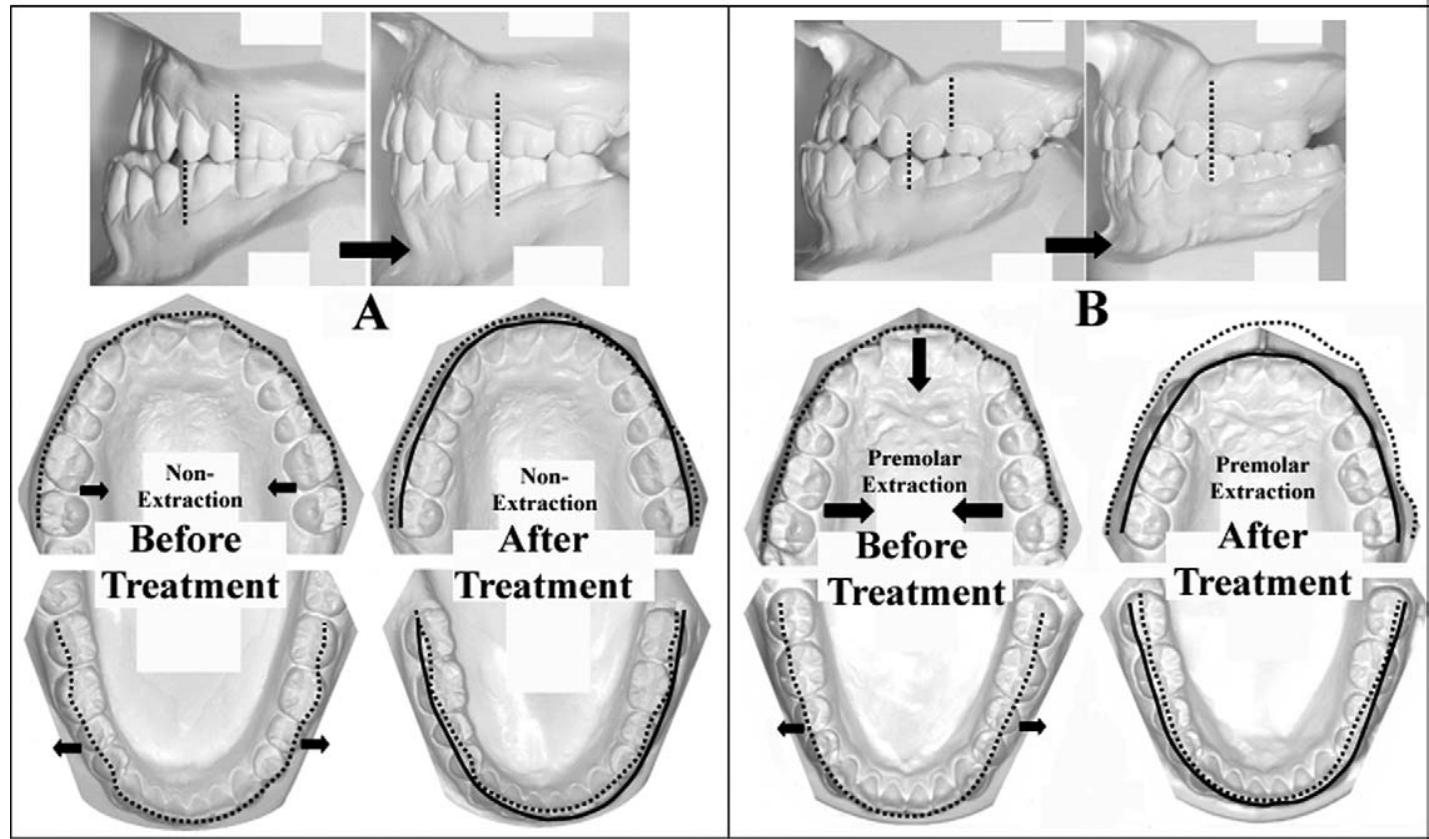

Fig 2. Representative dental casts show typical pattern of arch-width changes after A, nonextraction, and B, maxillary premolar extraction, in Class III surgical-orthodontic treatment. There was slight expansion of mandibular arch after treatment especially in premolar region in both patients (small arrows). However, superimposed dental arch (dotted line) shows greater arch width and length decreases in maxillary arch in extraction modality ( $B$, large arrows).

\section{Tooth movement}

The descriptive statistics for the angulation and inclination changes are shown in Table I. The pattern of mesiodistal tooth movement-an angulation change-was generally in the direction of uprighting to the occlusal plane. Angulation changes showed no significant differences between the 2 groups. In the mandibular dentition, the mean value indicated that the anterior teeth proclined. On the other hand, the posterior teeth angulated distally; this reflects the pattern of decrowding and decompensation mechanisms observed in the nonextraction modality.

The inclination changes measured at the posterior teeth indicated significant changes in both jaws; this contributed to better intermaxillary coordination. The maxillary posterior teeth showed palatal tipping, whereas all mandibular teeth uprighted buccally. The amount of palatal tipping of the maxillary posterior teeth was greater in the extraction group. On the other hand, the mandibular dentition had no significant differences between the 2 groups.

\section{Arch-width changes}

Dental arch constriction of the maxilla and expansion of mandibular arch width by orthodontic tooth movement were apparent; these resulted in an increase in the arch-width ratio. Figure 2 shows representative dental casts, illustrating typical patterns of arch-width changes.

Analysis of the data showed 2 important findings: arch-width change increases linearly with inclination change, and extraction of premolars appears to have some effect on arch-width changes. ANCOVA showed a significant extraction effect. Before proceeding with the ANCOVA, a separate regression on each line was performed to determine the slope (Fig 3). The interaction term of treatment variable (nonextraction versus extraction) and covariate (inclination change) was not significant, and the 2 slopes were parallel. Therefore, the homogeneity of regression could be inferred; this fulfilled the basic assumption of ANCOVA.

The values in Table I are the arithmetic means of the differences before and after treatment. Table II shows the adjusted means after controlling for the covariate-ie, the estimated marginal means. These are the tests of inclination-change adjusted means that account for the extraction effect irrespective of pretreatment positional variation. Table II showed that arch-width changes of the maxillary posterior teeth were significantly greater in the extraction group. Arch-width reduction was more than 2 times greater in the extraction group. 

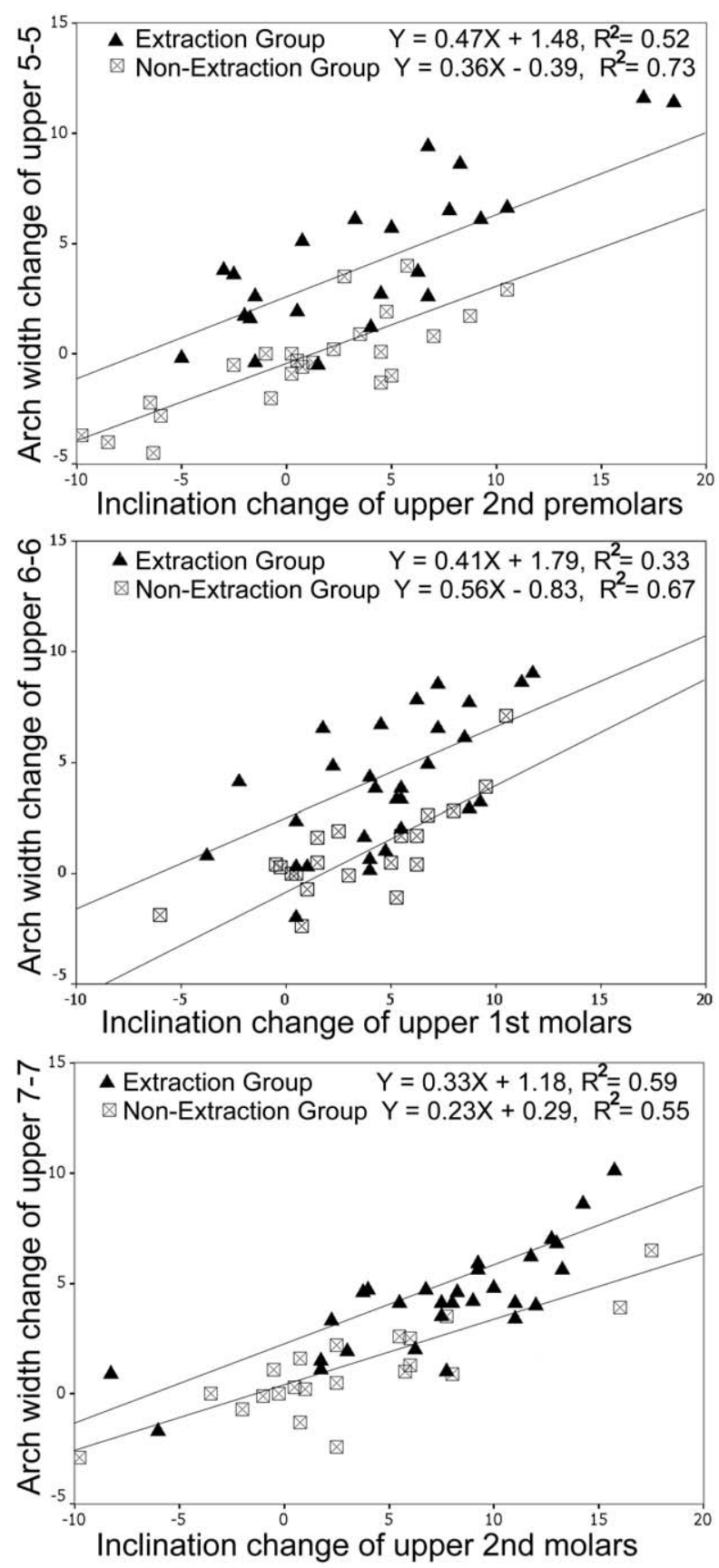

Fig 3. Scatterplots of arch-width changes of maxillary second premolar (top), first molar (middle), and second molar (bottom). Arch-width change was significantly greater in extraction than in nonextraction, indicated by larger $y$-intercept, although slopes were nearly same in both groups.

\section{DISCUSSION}

The angulation-and-inclination measuring gauge used in this study was originally developed to facilitate a setup model fabrication for lingual orthodontic treatment. After
Andrews introduced a protractor-type gauge in an attempt to develop a straight-wire appliance, ${ }^{15}$ many methods have been used to record tooth angulation and inclination. With advances in digital technology, such methods as elaborate wire bonding to the tooth surface in a tangent line and photometry, ${ }^{17}$ inclination protractor, ${ }^{18}$ torqueangulation reference guide, ${ }^{19}$ and modified torqueangulation reference guide g,21 $^{20}$ he been gradually replaced by a noninvasive 3-dimensional laser-scanning instrument. ${ }^{22,23}$ However, the disadvantages of measurement based on a 3-dimensional scanner are the increased time and limited practicability imposed on the practitioner, and the extensive hardware and software involved. Furthermore, inevitable errors are produced by the subject's micro-surface conformation. ${ }^{24}$ Therefore, in a clinical setting, the instrument we used is still useful and even more practical with acceptable reliability.

It is quite natural to have significant orthodontic tooth movement because the malocclusion is more severe in Class III mandibular prognathism. Even though there are diverse changes according to the individual teeth, a somewhat regular pattern of tooth movement can be found. Angulation changes showed no significant differences between the nonextraction and the maxillary premolar extraction groups. However, only the maxillary second molars showed a statistically significant angulation change. Also, there was more scatter in tooth movement for maxillary second molars than for the other teeth. It is likely that this change is caused by the correction of pretreatment distal tipping that is common in Class III malocclusion patients whose maxillae often have deficient room for posterior teeth (Fig 4).

Intermaxillary arch coordination can be separated into maxillary tooth movement, mandibular tooth movement, and anteroposterior surgical skeletal correction. Division of the coordination procedure into orthodontic and surgical components showed that maxillary arch correction was the major factor, since mandibular arch change had limitations in its correction, and the surgical amount was restricted to the predicted occlusion. Orthodontic tooth movements can be separated into mesiodistal and buccolingual components. These can be further explained by angulation change, inclination change, and bodily movement. Although the relationship between linear tooth movement and angular change of the posterior teeth follows more exactly a trigonometrical function, which forms a nonlinear curve, we can suppose that tooth movement is linearly related to the angular change within the envelope of ordinary orthodontic tooth movement. ${ }^{14}$ In fact, there was a high linear correlation coefficient, and, when posterior teeth 
Table II. Estimated marginal statistics* of arch-width changes in groups

\begin{tabular}{|c|c|c|c|c|c|c|}
\hline & Nonextraction & $\begin{array}{c}\text { Maxillary } \\
\text { first premolar } \\
\text { extraction }\end{array}$ & Extraction effect & Nonextraction & $\begin{array}{l}\text { Maxillary } \\
\text { first } \\
\text { premolar } \\
\text { extraction }\end{array}$ & Extraction effect \\
\hline & $D_{T 2-T 1} \pm S E$ & $D_{T 2-T 1} \pm S E$ & Sig & $D_{T 2-T I} \pm S E$ & $D_{T 2-T 1} \pm S E$ & Sig \\
\hline & \multicolumn{2}{|c|}{ Maxillary dentition } & \multicolumn{4}{|c|}{ Mandibular dentition } \\
\hline $3-3$ & $0.33 \pm 0.42$ & $1.29 \pm 0.37$ & & $-0.13 \pm 0.27$ & $0.63 \pm 0.23$ & \\
\hline $4-4$ & & & & $1.17 \pm 0.93$ & $2.51 \pm 0.80$ & \\
\hline $5-5$ & $-0.45 \pm 0.53$ & $-2.87 \pm 0.48$ & $\dagger$ & $2.07 \pm 0.63$ & $1.43 \pm 0.55$ & \\
\hline $6-6$ & $-1.16 \pm 0.47$ & $-3.53 \pm 0.39$ & $\doteqdot$ & $0.83 \pm 0.31$ & $1.08 \pm 0.25$ & \\
\hline $7-7$ & $-1.74 \pm 0.35$ & $-3.46 \pm 0.30$ & $\dagger$ & $2.27 \pm 0.35$ & $1.83 \pm 0.31$ & \\
\hline
\end{tabular}

*Estimated marginal means are group averages after removing effects of covariate, ie, inclination change that accounts for pretreatment positional variation. ${ }^{\dagger} P .01,{ }^{\ddagger} P .001 ; D_{T 2-T 1}$, mean differences before and after treatment; $S E$, standard error of mean differences. Sig, Significant difference between groups; 3 , Canine; 4 , first premolar; 5 , second premolar; 6 , first molar; 7 , second molar.

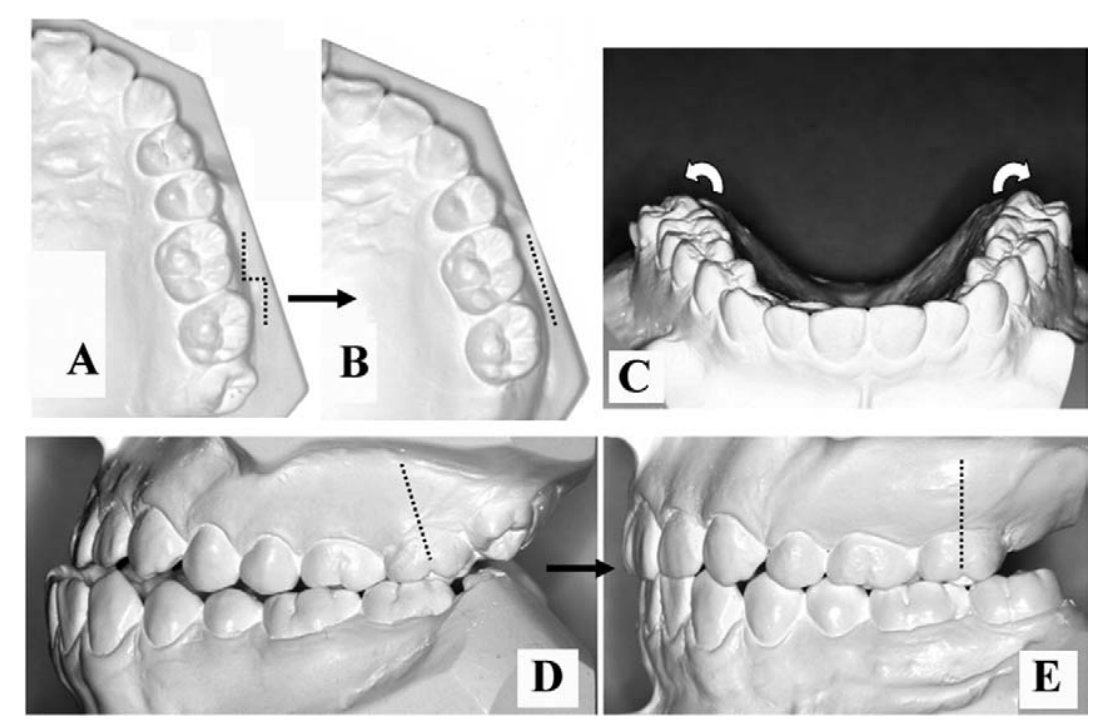

Fig 4. A, C, D, Maxillary second molar often shows buccal crown inclination and distal angulation before treatment; B, E, Orthodontic correction of maxillary second molar after treatment (dotted lines).

are moved, there is more tipping than bodily movement.

Figure 3 shows the amount of arch-width change compared with inclination change, taking into account the extraction effect. We used different points for the 2 groups and plotted the data against the inclination change. It is evident from the graph that the data are linearly related to the inclination change. This graph could result in a more informative explanation, for both analyzing the impact of inclination change on archwidth change and determining whether extraction has an effect. ANCOVA showed a significant extraction effect. There was a significantly greater reduction in the inclination of the maxillary posterior teeth in the extraction group than in the nonextraction group, notably in arch-width change. The key issue in this com- parison was that the arch-width reduction was greater in the extraction site when controlling for the amount of orthodontic tooth movement. This information indicates that, when the posterior teeth of the deficient maxilla are more flared, the possibility of maxillary premolar extraction increases. With extractions, it is expected that the maxillary molars will slide mesially somewhat to close the extraction space; this causes a Class II molar relationship after anteroposterior surgical correction.

In contrast, without extractions, all transverse correction must occur through inclination changes. Because there is no mesiodistal tooth movement, the arch-width changes would follow the inclination change more exactly. Also, decreasing arch width increases arch length because of the linear relationship between arch 
width and length. ${ }^{13}$ Decreased arch width is associated with a reduction in arch depth: a 3-mm reduction in arch width is known to be equivalent to a $1-\mathrm{mm}$ increase in overjet. ${ }^{13}$ Furthermore, transverse arch correction is well known to be an unstable treatment modality, ${ }^{25,26}$ and the arch-width reduction is more likely to be unstable without extractions and is most ineffective in the posterior region. ${ }^{27}$

The importance of the transverse dental relationships between arch width and preexisting posterior tooth inclination are sometimes overlooked by orthodontists who are more concerned about surgical jaw repositioning and facial esthetics after surgery. Proper transverse dental relationships are necessary to achieve maximum occlusal function. In this respect, there is an indication to expand or to reduce the dental arch in the maxilla by surgical procedures. Because transverse and anteroposterior maxillary deficiency is often seen with mandibular prognathism, patients who require maxillary advancement can be corrected with 3- or 4-segment maxillary osteotomy simultaneously for intermaxillary arch congruity. However, segmentation of the maxilla increases the risk for skeletal, dental, and periodontal complications that do not occur when the maxilla is not segmented. ${ }^{6,7,11}$ Surgically assisted rapid maxillary expansion has been recommended for older patients. ${ }^{12}$ However, in a patient with mild transverse maxillary deficiency, we prefer maxillary premolar extraction with greater surgical jaw repositioning rather than surgical transverse correction.

How can this result be used for further Class III surgical-orthodontic treatment planning? How can the need for maxillary premolar extraction be quantified? Formerly, it was our experience that, after mandibular setback surgery, when the surgical wafer was removed, a congruent arch at the time of presurgical simulation surgery yielded a less-thansatisfactory posterior occlusion. Our previous experiences of treatment failure indicated that buccally flared maxillary posterior teeth often produced progressive lingual crossbites after surgery. Additionally, increased tongue pressures against the distally repositioned mandible, which can upright the mandibular posterior teeth into a buccal direction, might be another cause of progressive crossbite. We learned from these experiences that not only arch width but also posterior tooth inclination must be considered to achieve harmonious intermaxillary arch coordination after surgery. Based on our findings and the continued examination of recent patients, we suggest a supplementary indication for maxillary premolar extraction to improve the posttreatment occlusal outcome of Class III surgical-orthodontic treatments. Complex numerical algorithms are generally not required to establish presurgical treatment planning. The best method is to make a diagnostic setup model that simulates the posttreatment occlusion, however, this procedure is practically difficult. Instead, for both clinical reasons and ease of application, the following method is used to predict the requirement for maxillary premolar extraction to correct mild transverse problems: First, posttreatment occlusion is simulated with hand-held articulated models (Fig 5, A). Second, from the distal side of the articulated dental casts, occlusal features can be observed and an imaginary line drawn that could be achieved by orthodontic tooth movement. Before this can have diagnostic applicability, the limitations and the general range of orthodontic tooth movement must be established. For this purpose, the envelope of discrepancy ${ }^{28}$ and the research of Kim et $\mathrm{al}^{14}$ suggested some ideas. But, in practice, every orthodontist is well aware of the feasible amount of tooth movement through experience. Third, if plausible tooth movement cannot be expected, a Class II molar relationship might be another alternative (Fig 5,D), and the same simulation procedure repeated. This situation suggests that there is a transverse problem of the maxilla. This procedure could imply the need for maxillary premolar extraction. These suggestions acknowledge, of course, the prior importance of esthetics and the amount of crowding for planning maxillary premolar extractions. ${ }^{29-32}$ This method is especially advantageous if the patient requires more mandibular setback for esthetic reasons, not including maxillary advancement surgery. We assume that fairly wellarranged surgical orthodontic procedures can be performed with these estimates.

The reference plane we used was the functional occlusal plane. Because orthodontic tooth movement was interpreted only in the transverse plane, an assessment of tooth movement in the vertical direction could not be considered. In addition, in this type of treatment, the relationship between occlusal stability and transverse orthodontic tooth movement, and the role of the curve of Wilson in transverse relapse, should be further investigated.

\section{CONCLUSIONS}

This article focused on the transverse effect of maxillary premolar extraction in the Class III presurgical orthodontic treatment plan and also highlights the indication for maxillary premolar extraction to correct mild transverse problems of the maxilla. When both clinicians-orthodontist and surgeon-make a presurgical orthodontic plan, the decision for maxillary premolar extraction is included before the treatment begins. 


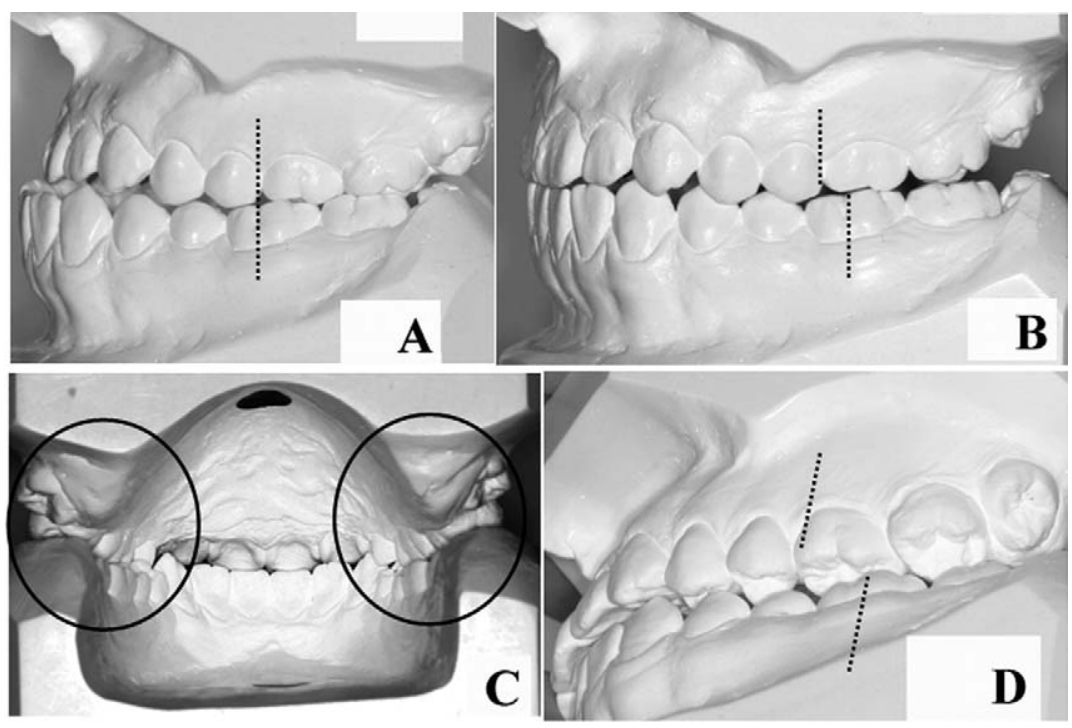

Fig 5. To decide whether maxillary premolar extraction is preferable, simple strategy to simulate posttreatment occlusion is hand-held articulated dental models. A, Pretreatment occlusion; $\mathbf{B}$, simulated articulation at Class I molar relationship; $\mathbf{C}$, at this time, bilateral buccal scissor-bite is generally observed. From distal side of hand-articulated dental casts, occlusal feature can be observed, with imaginary line drawn that could be achieved by orthodontic tooth movement. D, If plausible tooth movement cannot be expected, Class II molar relationship might be another alternative, and same simulation procedure is repeated.

As part of the various criteria for those extractions, buccally flared maxillary teeth could be added. Indications and proper treatment strategy for Class III surgical orthodontics with maxillary premolar extraction depend partly on the magnitude of the transverse interarch coordination (or problem), especially in the maxillary dentition.

The authors thank the anonymous reviewers who read and commented upon this paper. The authors also express gratitude to the copyeditor, American Journal of Orthodontics and Dentofacial Orthopedics, and Dr Hyewon Kim for their invaluable assistance to improve this manuscript.

\section{REFERENCES}

1. Lee SJ, Kim TW, Suhr CH. Recognition of malocclusion and orthodontic treatment. Korean J Orthod 1994;24:193-8.

2. Im DH, Kim TW, Nahm DS, Chang YI. Current trends in orthodontic patients in Seoul National University Dental Hospital. Korean J Orthod 2003;33:63-72.

3. Guyer EC, Ellis E, McNamara JA Jr, Behrents RG. Components of Class III malocclusion in juveniles and adolescents. Angle Orthod 1986;56:7-30.

4. McNamara JA. Maxillary transverse deficiency. Am J Orthod Dentofacial Orthop 2000;117:567-70.

5. Collins SM, Poulton DR. Orthodontic and orthognathic surgical correction of Class III malocclusion. Angle Orthod 1976;46:312-31.
6. Proffit WR. Treatment planning: the search for wisdom. In: Proffit WR, White RP, editors. Surgical-orthodontic treatment. St Louis: Mosby; 1990. p. 142-9.

7. Takeuchi M, Tanaka E, Nonoyama D, Aoyama J, Tanne K. An adult case of skeletal open bite with a severely narrowed maxillary dental arch. Angle Orthod 2002;72:362-70.

8. Conley RS, Legan HL. Correction of severe vertical maxillary excess with anterior open bite and transverse maxillary deficiency. Angle Orthod 2002;72:265-74.

9. Krekmanov L, Kahnberg KE. Transverse surgical correction of the maxilla. J Craniomaxillofac Surg 1990;18:332-4.

10. Turvey TA. Maxillary expansion: a surgical technique based on surgical-orthodontic treatment objectives and anatomical considerations. J Maxillofac Surg 1985;13:51-8.

11. Lehman JA Jr, Haas AJ. Surgical-orthodontic correction of transverse maxillary deficiency. Dent Clin North Am 1990;34:385-95.

12. Phillips C, Medland WH, Fields HW, Proffit WR, White RP Jr. Stability of surgical maxillary expansion. Int J Adult Orthod Orthognath Surg 1992;7:139-46.

13. Lee RT. Arch width and form: a review. Am J Orthod Dentofacial Orthop 1999;115:305-13.

14. Kim SJ, Park SY, Woo HH, Park EJ, Kim YH, Lee SJ, et al. A study on the limit of orthodontic treatment. Korean J Orthod 2004;34:239-45.

15. Andrews LF. Straight wire: the concept and appliance. San Diego: LA Wells; 1986. p. 14-31.

16. Dahlberg G. Statistical methods for medical and biological students. New York: Interscience Publishers; 1940. p. 122-32.

17. Kim JS, Jin KH, Hong SJ. A statistical study of clinical crown inclination naturally occuring optimal occlusion in Korean. Korean J Orthod 1992;22:715-33. 
18. Richmond S, Klufas ML, Sywanyk M. Assessing incisor inclination: a non-invasive technique. Eur J Orthod 1998;20:721-6.

19. Fillion D, Leclerc JF. Lingual orthodontics: why is it progressing? Orthod Fr 1991;62:793-801.

20. Wiechmann D. Lingual orthodontics (part 1): laboratory procedure. J Orofac Orthop 1999;60:371-9.

21. Kwon OW, Hwang HS. A new method of tooth positioner fabrication using modified TARG to measure the inclination and angulation of individual teeth. Korean J Orthod 1999;29:137-46.

22. Chang YI, Yang WS, Nahm DS, Moon SC. A study for the development of the Korean orthodontic bracket. Korean J Orthod 2000;30:565-78.

23. Kusayama M, Motohashi N, Kuroda T. Relationship between transverse dental anomalies and skeletal asymmetry. Am J Orthod Dentofacial Orthop 2003;123:329-37.

24. Chang YJ, Kim TW, Yoo KH. The effect of variation in the vertical position of bracket on crown inclination. Korean J Orthod 2002;32: 401-12.

25. Del Santo M Jr, English JD, Wolford LM, Gandini LG Jr. Midsymphyseal distraction osteogenesis for correcting transverse mandibular discrepancies. Am J Orthod Dentofacial Orthop 2002; 121:629-38.
26. Kahl-Nieke B, Fischbach H, Schwarze CW. Treatment and postretention changes in dental arch width dimensions-a longterm evaluation of influencing cofactors. Am J Orthod Dentofacial Orthop 1996;109:368-78.

27. Gardner SD, Chaconas SJ. Posttreatment and postretention changes following orthodontic therapy. Angle Orthod 1976;46: 151-61.

28. Proffit WR, White RP. The need for surgical-orthodontic treatment. In: Proffit WR, White RP, editors. Surgical-orthodontic treatment. St Louis: Mosby; 1990. p. 3-4.

29. Wolford LM, Chemello PD, Hilliard F. Occlusal plane alteration in orthognathic surgery-part I: effects on function and esthetics. Am J Orthod Dentofacial Orthop 1994;106:304-16.

30. Poulton DR. Surgical orthodontics: maxillary procedures. Angle Orthod 1976;46:312-31.

31. Arnett GW, Jelic JS, Kim J, Cummings DR, Beress A, Worley CM, et al. Soft tissue cephalometric analysis: diagnosis and treatment planning of dentofacial deformity. Am J Orthod Dentofacial Orthop 1999;116:239-53.

32. Jacobs JD, Sinclair PM. Principles of orthodontic mechanics in orthognathic surgery cases. Am J Orthod 1983;84:399-407.

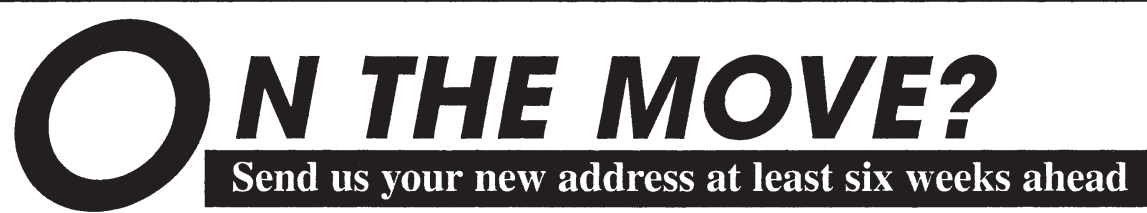

Don't miss a single issue of the journal! To ensure prompt service when you change your address, please photocopy and complete the form below.

Please send your change of address notification at least six weeks before your move to ensure continued service. We regret we cannot guarantee replacement of issues missed due to late notification.

\section{JOURNAL TITLE:}

Fill in the title of the journal here.

\section{OLD ADDRESS:}

Affix the address label from a recent issue of the journal here.

\section{NEW ADDRESS: \\ Clearly print your new address here.}

Name

Address

City/State/ZIP

\section{INDIVIDUAL SUBSCRIBERS}

\section{COPY AND MAIL THIS FORM TO:}

Elsevier Inc.

Subscription Customer Service

6277 Sea Harbor Dr

Orlando, FL 32887
OR FAX TO:
407-363-9661

OR E-MAIL:

elspcs@elsevier.com
OR PHONE:

800-654-2452

Outside the U.S., call

407-345-4000 